\title{
Vector-valued metrics, fixed points and coupled fixed points for nonlinear operators
}

\author{
Adrian Petruşel, Gabriela Petruşel and Cristina Urs ${ }^{*}$
}

"Correspondence:

cristina.urs@math.ubbcluj.ro

Babeş-Bolyai University

Cluj-Napoca, Kogălniceanu Street

no. 1, Cluj-Napoca, 400084, Romania

\begin{abstract}
In this paper, we will present fixed point theorems for singlevalued and multivalued operators in spaces endowed with vector-valued metrics, as well as a Gnana Bhaskar-Lakshmikantham-type theorem for the coupled fixed point problem, associated to a pair of singlevalued operators (satisfying a generalized mixed monotone property) in ordered metric spaces. The approach is based on Perov-type fixed point theorems in spaces endowed with vector-valued metrics. The Ulam-Hyers stability and the limit shadowing property of the fixed point problems are also discussed.

MSC: $47 \mathrm{H} 10 ; 54 \mathrm{H} 25$

Keywords: singlevalued operator; multivalued operator; vector-valued metric; fixed point; ordered metric space; coupled fixed point; Ulam-Hyers stability; limit shadowing property
\end{abstract}

\section{Introduction}

The classical Banach contraction principle is a very useful tool in nonlinear analysis with many applications to operatorial equations, fractal theory, optimization theory and other topics. Banach contraction principle was extended for singlevalued contraction on spaces endowed with vector-valued metrics by Perov [1] and Perov and Kibenko [2]. For some other contributions to this topic, we also refer to [3-9], etc. The case of multivalued contractions on spaces endowed with vector-valued metrics is treated in [10-12], etc.

In the study of the fixed points for an operator, it is sometimes useful to consider a more general concept, namely coupled fixed points. The concept of coupled fixed point for nonlinear operators was introduced and studied by Opoitsev (see [13-15]) and then, in 1987, by Guo and Lakshmikantham (see [16]) in connection with coupled quasisolutions of an initial value problem for ordinary differential equations. Later, a new research direction for the theory of coupled fixed points in ordered metric spaces was initiated by Gnana Bhaskar and Lakshmikantham in [17] and by Lakshmikantham and Cirić in [18]. Their approach is based on some contractive type conditions on the operator. For other results on coupled fixed point theory, see [17-22], etc.

Let us recall first some important preliminary concepts and results.

Let $X$ be a nonempty set. A mapping $d: X \times X \rightarrow \mathbb{R}^{m}$ is called a vector-valued metric on $X$ if the following properties are satisfied:

(a) $d(x, y) \geq O$ for all $x, y \in X$; if $d(x, y)=O$, then $x=y$ (where $O:=\underbrace{(0,0, \ldots, 0)}_{m \text {-times }})$;

( 2013 Petrusel et al.; licensee Springer. This is an Open Access article distributed under the terms of the Creative Commons Attribution License (http://creativecommons.org/licenses/by/2.0), which permits unrestricted use, distribution, and reproduction in any medium, provided the original work is properly cited. 
(b) $d(x, y)=d(y, x)$ for all $x, y \in X$;

(c) $d(x, y) \leq d(x, z)+d(z, y)$ for all $x, y \in X$.

A nonempty set $X$ endowed with a vector-valued metric $d$ is called a generalized metric space in the sense of Perov (in short, a generalized metric space), and it will be denoted by $(X, d)$. The notions of convergent sequence, Cauchy sequence, completeness, open and closed subset, open and closed ball, ... are similar to those for usual metric spaces.

Notice that the generalized metric space in the sense of Perov is a particular case of Riesz spaces (see $[23,24])$ and of so-called cone metric spaces (or $K$-metric space) (see $[25,26])$.

We denote by $M_{m m}\left(\mathbb{R}_{+}\right)$the set of all $m \times m$ matrices with positive elements and by $I$ the identity $m \times m$ matrix. If $x, y \in \mathbb{R}^{m}, x=\left(x_{1}, \ldots, x_{m}\right)$ and $y=\left(y_{1}, \ldots, y_{m}\right)$, then, by definition

$$
x \leq y \quad \text { if and only if } \quad x_{i} \leq y_{i} \quad \text { for } i \in\{1,2, \ldots, m\}
$$

Notice that through this paper, we will make an identification between row and column vectors in $\mathbb{R}^{m}$.

Definition 1.1 A square matrix of real numbers is said to be convergent to zero if and only if its spectral radius $\rho(A)$ is strictly less than 1 . In other words, this means that all the eigenvalues of $A$ are in the open unit disc, i.e., $|\lambda|<1$, for every $\lambda \in \mathbb{C}$ with $\operatorname{det}(A-\lambda I)=0$, where $I$ denotes the unit matrix of $\mathcal{M}_{m, m}(\mathbb{R})$ (see [27]).

A classical result in matrix analysis is the following theorem (see $[27,28])$.

Theorem 1.2 Let $A \in M_{m m}\left(\mathbb{R}_{+}\right)$. The following assertions are equivalent

(i) A is convergent towards zero;

(ii) $A^{n} \rightarrow O$ as $n \rightarrow \infty$;

(iii) The matrix $(I-A)$ is nonsingular and

$$
(I-A)^{-1}=I+A+\cdots+A^{n}+\cdots
$$

(iv) The matrix $(I-A)$ is nonsingular and $(I-A)^{-1}$ has nonnegative elements;

(v) $A^{n} q \rightarrow O$ and $q A^{n} \rightarrow O$ as $n \rightarrow \infty$, for each $q \in \mathbb{R}^{m}$;

(vi) The matrices $q A$ and $A q$ converge to $O$ for each $q \in(1, Q)$, where $Q:=\frac{1}{\rho(A)}$.

If $X$ is a nonempty set and $f: X \rightarrow X$ is an operator, then

$$
\operatorname{Fix}(f):=\{x \in X ; x=f(x)\}
$$

We recall now Perov's fixed point theorem (see [1], see also [2]).

Theorem 1.3 (Perov) Let $(X, d)$ be a complete generalized metric space, and let the operator $f: X \rightarrow X$ be with the property that there exists a matrix $A \in M_{m m}\left(\mathbb{R}_{+}\right)$convergent towards zero such that

$$
d(f(x), f(y)) \leq A d(x, y), \quad \text { for all } x, y \in X
$$

Then

(1) $\operatorname{Fix}(f)=\left\{x^{*}\right\}$; 
(2) the sequence of successive approximations $\left(x_{n}\right)_{n \in \mathbb{N}}, x_{n}:=f^{n}\left(x_{0}\right)$ is convergent in $X$ to $x^{*}$, for all $x_{0} \in X$

(3) one has the following estimation

$$
d\left(x_{n}, x^{*}\right) \leq A^{n}(I-A)^{-1} d\left(x_{0}, x_{1}\right)
$$

(4) if $g: X \rightarrow X$ is an operator such that there exists $y^{*} \in \operatorname{Fix}(g)$, and there exists $\eta:=\left(\eta_{1}, \ldots, \eta_{m}\right) \in \mathbb{R}_{+}^{m}$ with $\eta_{i}>0$ for each $i \in\{1,2, \ldots, m\}$ such that

$$
d(f(x), g(x)) \leq \eta, \quad \text { for each } x \in X,
$$

then

$$
d\left(x^{*}, y^{*}\right) \leq(I-A)^{-1} \eta
$$

(5) if $g: X \rightarrow X$ is an operator, $y_{n}:=g^{n}\left(x_{0}\right)$, and there exists $\eta:=\left(\eta_{1}, \ldots, \eta_{m}\right) \in \mathbb{R}_{+}^{m}$ with $\eta_{i}>0$ for each $i \in\{1,2, \ldots, m\}$ such that

$$
d(f(x), g(x)) \leq \eta, \quad \text { for all } x \in X,
$$

we have the following estimation

$$
d\left(y_{n}, x^{*}\right) \leq(I-A)^{-1} \eta+A^{n}(I-A)^{-1} d\left(x_{o}, x_{1}\right) .
$$

Notice that in Precup [9], as well as in [3, 5] and [7] are pointed out the advantages of working with vector-valued norm with respect to the usual scalar norms.

There is a vast literature concerning this approach, see also, for example, $[4,6,8,9,29]$, etc.

We will focus our attention to the following system of operatorial equations

$$
\left\{\begin{array}{l}
x=T_{1}(x, y), \\
y=T_{2}(x, y),
\end{array}\right.
$$

where $T_{1}, T_{2}: X \times X \rightarrow X$ are two given operators.

By definition, a solution $(x, y) \in X \times X$ of the above system is called a coupled fixed point for the operators $T_{1}$ and $T_{2}$. Notice that if $S: X \times X \rightarrow X$ is an operator and we define

$$
T_{1}(x, y):=S(x, y) \quad \text { and } \quad T_{2}(x, y):=S(y, x)
$$

then we get the classical concept of a coupled fixed point for the operator $S$ introduced by Opoitsev and then intensively studied in some papers by Guo and Lakshmikantham, Gnana Bhaskar and Lakshmikantham, Lakshmikantham and Ćirić, etc.

The case of an operatorial inclusion is defined in a similar way, namely, by using the symbol $\in$ instead of $=$. The concept of a coupled fixed point for a multivalued operator $S$ is accordingly defined. 
First aim of this work is to present some existence and stability results for fixed point equations and inclusions in generalized metric spaces in the sense of Perov. Our second purpose is to present, in the setting of an ordered metric space, a Gnana BhaskarLakshmikantham-type theorem for the coupled fixed point problem associated to a pair of singlevalued operators satisfying a generalized mixed monotone assumption. The approach is based on an abstract fixed point theorem in ordered complete metric spaces. Our results are related with other existence and stability results for the a coupled fixed point problem for singlevalued operators proved in [30] by the support of Perov's fixed point theorem.

\section{Existence, uniqueness and stability for fixed point equations and inclusions}

We start this section by an extension of Perov's theorem. At the same time, the result is a generalization to vector-valued metric spaces of the main theorem in [31].

Theorem 2.1 Let $(X, d)$ be a generalized complete metric space, and let $f: X \rightarrow X$ be an almost contraction with matrices $A, B$ and $C$, i.e., the matrix $A+C \in M_{m m}\left(\mathbb{R}_{+}\right)$converges to zero, $B \in M_{m m}\left(\mathbb{R}_{+}\right)$and

$$
d(f(x), f(y)) \leq A d(x, y)+B d(y, f(x))+C d(x, f(x)), \quad \text { for all } x, y \in X
$$

Then, the following conclusions hold

1. $f$ has at least one fixed point in $X$ and, for each $x_{0} \in X$, the sequence $x_{n}:=f^{n}\left(x_{0}\right)$ of successive approximations off starting from $x_{0}$ converges to $x^{*}\left(x_{0}\right) \in \operatorname{Fix}(f)$ as $n \rightarrow \infty$;

2. For each $x_{0} \in X$, we have

$$
d\left(x_{n}, x^{*}\left(x_{0}\right)\right) \leq A^{n}(I-A)^{-1} d\left(x_{0}, f\left(x_{0}\right)\right), \quad \text { for all } n \in \mathbb{N}
$$

and

$$
d\left(x_{0}, x^{*}\left(x_{0}\right)\right) \leq(I-A)^{-1} d\left(x_{0}, f\left(x_{0}\right)\right)
$$

3. If, additionally, the matrix $A+B$ converges to zero, then $f$ has a unique fixed point in $X$.

Proof Let $x_{0} \in X$ be arbitrary, and consider $\left(x_{n}\right)_{n \in \mathbb{N}}$ the sequence of successive approximations for $f$ starting from $x_{0}$, i.e.,

$$
x_{n+1}=f\left(x_{n}\right), \quad \text { for all } n \in \mathbb{N} \text {. }
$$

We have that $d\left(x_{1}, x_{2}\right)=d\left(f\left(x_{0}\right), f\left(x_{1}\right)\right) \leq A d\left(x_{0}, x_{1}\right)+B d\left(x_{1}, f\left(x_{0}\right)\right)+C d\left(x_{0}, f\left(x_{0}\right)\right)=(A+$ C) $d\left(x_{0}, x_{1}\right)$.

Inductively, we get that the sequence $\left(x_{n}\right)_{n \in \mathbb{N}}$ satisfies, for all $n \in \mathbb{N}$, the following estimation

$$
d\left(x_{n}, x_{n+1}\right) \leq(A+C)^{n} d\left(x_{0}, x_{1}\right)
$$


Hence, for all $n \in \mathbb{N}$ and $p \in \mathbb{N}, p \geq 1$, we get that

$$
\begin{aligned}
d\left(x_{n}, x_{n+p}\right) & \leq d\left(x_{n}, x_{n+1}\right)+d\left(x_{n+1}, x_{n+2}\right)+\cdots+d\left(x_{n+p-1}, x_{n+p}\right) \\
& \leq(A+C)^{n} d\left(x_{0}, x_{1}\right)+(A+C)^{n+1} d\left(x_{0}, x_{1}\right)+\cdots+(A+C)^{n+p-1} d\left(x_{0}, x_{1}\right) \\
& \leq(A+C)^{n}\left[I+(A+C)+(A+C)^{2}+\cdots+(A+C)^{p-1}+\cdots\right] d\left(x_{0}, x_{1}\right) \\
& \leq(A+C)^{n}[I-(A+C)]^{-1} d\left(x_{0}, x_{1}\right) .
\end{aligned}
$$

Thus, $d\left(x_{n}, x_{n+p}\right) \rightarrow O$, as $n \rightarrow \infty$. Hence $\left(x_{n}\right)_{n \in \mathbb{N}}$ is a Cauchy sequence in the complete metric space $(X, d)$. Thus, $\left(x_{n}\right)_{n \in \mathbb{N}}$ converges to a certain element $x^{*}\left(x_{0}\right) \in X$.

Next, we show that $x^{*}:=x^{*}\left(x_{0}\right) \in \operatorname{Fix}(f)$. Indeed, we have the following estimation

$$
\begin{aligned}
d\left(x^{*}, f\left(x^{*}\right)\right) & \leq d\left(x^{*}, x_{n}\right)+d\left(x_{n}, f\left(x^{*}\right)\right)=d\left(x^{*}, x_{n}\right)+d\left(f\left(x_{n-1}\right), f\left(x^{*}\right)\right) \\
& \leq d\left(x^{*}, x_{n}\right)+A d\left(x_{n-1}, x^{*}\right)+B d\left(x^{*}, x_{n}\right)+C d\left(x_{n-1}, x_{n}\right) \rightarrow O, \quad \text { as } n \rightarrow \infty .
\end{aligned}
$$

Hence $x^{*} \in \operatorname{Fix}(f)$. In addition, letting $p \rightarrow \infty$ in the estimation of $d\left(x_{n}, x_{n+p}\right)$, we get

$$
d\left(x_{n}, x^{*}\left(x_{0}\right)\right) \leq(A+C)^{n}[I-(A+C)]^{-1} d\left(x_{0}, f\left(x_{0}\right)\right), \quad \text { for all } n \in \mathbb{N} .
$$

For $n=0$, we obtain

$$
d\left(x_{0}, x^{*}\left(x_{0}\right)\right) \leq(A+C)^{n}[I-(A+C)]^{-1} d\left(x_{0}, f\left(x_{0}\right)\right) .
$$

We show now the uniqueness of the fixed point.

Let $x^{*}, y^{*} \in \operatorname{Fix}(f)$ with $x^{*} \neq y^{*}$. Then

$$
\begin{aligned}
d\left(x^{*}, y^{*}\right) & =d\left(f\left(x^{*}\right), f\left(y^{*}\right)\right) \leq A d\left(x^{*}, y^{*}\right)+B d\left(y^{*}, f\left(x^{*}\right)\right)+C d\left(x^{*}, f\left(x^{*}\right)\right) \\
& =(A+B) d\left(x^{*}, y^{*}\right) .
\end{aligned}
$$

Thus $(I-A-B) d\left(x^{*}, y^{*}\right) \leq O \in \mathbb{R}^{m}$. Since $A+B$ converges to zero, we get that $I-A-B$ is non-singular and $(I-A-B)^{-1} \in M_{m, m}\left(\mathbb{R}_{+}\right)$. Hence $d\left(x^{*}, y^{*}\right) \leq O$ and so $x^{*}=y^{*}$.

Remark 2.2 The result above extends Corollary 2.3 in [5], where the case of almost contractions with matric $C=O$ is treated.

Two important abstract concepts are given now.

Definition 2.3 (see [32,33]) If $(X, d)$ is a generalized metric space, then $f: X \rightarrow X$ is called a weakly Picard operator if and only if the sequence $\left(f^{n}(x)\right)_{n \in \mathbb{N}}$ of successive approximations of $f$ converges for all $x \in X$ and the limit (which may depend on $x$ ) is a fixed point of $f$.

If $f$ is weakly Picard operator, then we define the operator $f^{\infty}: X \rightarrow X$ by

$$
f^{\infty}(x):=\lim _{n \rightarrow \infty} f^{n}(x)
$$


Notice that, in this case, $f^{\infty}(X)=\operatorname{Fix}(f)$. Moreover, $f^{\infty}$ is a set retraction of $X$ to $\operatorname{Fix}(f)$.

If $f$ is weakly Picard operator and $\operatorname{Fix}(f)=\left\{x^{*}\right\}$, then by definition $f$ is a Picard operator. In this case, $f^{\infty}$ is the constant operator, i.e., $f^{\infty}(x)=x^{*}$ for all $x \in X$.

Definition 2.4 (see [33]) Let $(X, d)$ be a generalized metric space, and let $f: X \rightarrow X$ be an operator. Then, $f$ is said to be a $\psi$-weakly Picard operator if and only if $f$ is a weakly Picard operator and $\psi: \mathbb{R}_{+}^{m} \rightarrow \mathbb{R}_{+}^{m}$ is an increasing operator, continuous in $O$ with $\psi(O)=O$ such that

$$
d\left(x, f^{\infty}(x)\right) \leq \psi(d(x, f(x)), \quad \text { for all } x \in X
$$

Moreover, a $\psi$-weakly Picard operator $f: X \rightarrow X$ with a unique fixed point is said to be a $\psi$-Picard operator. In particular, if $\psi: \mathbb{R}_{+}^{m} \rightarrow \mathbb{R}_{+}^{m}$ is given by $\psi(t)=M \cdot t$ (with $C \in M_{m m}\left(\mathbb{R}_{+}\right)$), then we say that $f$ is $M$-weakly Picard operator (respectively a $M$-Picard operator).

From Theorem 2.1, we get the following example.

Example 2.5 If $(X, d)$ is a generalized complete metric space and $f: X \rightarrow X$ is an almost contraction with matrices $A, B$, and $C$, then $f$ is a $\psi$-weakly Picard operator with the function $\psi(t):=[I-(A+C)]^{-1} t$. In particular, if $f: X \rightarrow X$ is a contraction with matrix $A$, then $f$ is a $\psi$-Picard operator with $\psi(t):=(I-A)^{-1} t$.

For the proof of our next theorems we need the following notion.

Definition 2.6 Let $(X, d)$ be a generalized metric space, and let $f: X \rightarrow X$ be an operator. Then, the fixed point equation

$$
x=f(x)
$$

is said to be generalized Ulam-Hyers stable if there exists an increasing function $\psi: \mathbb{R}_{+}^{m} \rightarrow$ $\mathbb{R}_{+}^{m}$, continuous in $O$ with $\psi(O)=O$ such that for any $\varepsilon:=\left(\varepsilon_{1}, \ldots, \varepsilon_{m}\right)$ with $\varepsilon_{i}>0$ for $i \in$ $\{1, \ldots, m\}$ and any $\varepsilon$-solution $y^{*} \in X$ of (4), i.e.,

$$
d\left(y^{*}, f\left(y^{*}\right)\right) \leq \varepsilon
$$

there exists a solution $x^{*}$ of (4) such that

$$
d\left(x^{*}, y^{*}\right) \leq \psi(\varepsilon)
$$

In particular, if $\psi(t)=C \cdot t, t \in \mathbb{R}_{+}^{m}$ (where $\left.C \in M_{m m}\left(\mathbb{R}_{+}\right)\right)$, then the fixed point equation (4) is called Ulam-Hyers stable.

We can prove now the following abstract result (see also Rus [33]) concerning the UlamHyers stability of the fixed point equation (4).

Theorem 2.7 Let $(X, d)$ be a generalized metric space, and let $f: X \rightarrow X$ be a $\psi$-weakly Picard operator. Then, the fixed point equation (4) is generalized Ulam-Hyers stable. 
Proof Let $\varepsilon:=\left(\varepsilon_{1}, \ldots, \varepsilon_{m}\right)$ (with $\varepsilon_{i}>0$ for $i \in\{1, \ldots, m\}$ ), and let $y^{*} \in X$ be a $\varepsilon$-solution of (5), i.e., $d\left(y^{*}, f\left(y^{*}\right)\right) \leq \varepsilon$. Since $f$ is a $\psi$-Picard operator, we have that

$$
d\left(x, f^{\infty}(x)\right) \leq \psi(d(x, f(x)), \quad \text { for each } x \in X
$$

Hence, there exists $x^{*}:=f^{\infty}\left(y^{*}\right) \in \operatorname{Fix}(f)$ such that

$$
d\left(y^{*}, f^{\infty}\left(y^{*}\right)\right) \leq \psi\left(d\left(y^{*}, f\left(y^{*}\right)\right) \leq \psi(\varepsilon) .\right.
$$

Remark 2.8 In particular, if $(X, d)$ is a generalized complete metric space, and $f: X \rightarrow X$ is an almost contraction with matrices $A, B$ and $C$, then, by Example 2.5 and Theorem 2.7, we get that the fixed point equation (4) is Ulam-Hyers stable.

We now move our attention to the multivalued case. If $(X, \rho)$ is a metric space, and we denote by $P(X)$ the space of all nonempty subsets of $X$, then the gap functional (generated by $\rho$ ) on $P(X)$ is defined as

$$
D_{\rho}: P(X) \times P(X) \rightarrow \mathbb{R}_{+}, \quad D_{\rho}(A, B):=\inf \{\rho(a, b) \mid a \in A, b \in B\} .
$$

In particular, if $x_{0} \in X$, we put $D_{\rho}\left(x_{0}, B\right)$ in place of $D_{\rho}\left(\left\{x_{0}\right\}, B\right)$.

We will denote by $H_{\rho}$ the Pompeiu-Hausdorff functional on $P(X)$, defined as

$$
H_{\rho}: P(X) \times P(X) \rightarrow \mathbb{R}_{+} \cup\{+\infty\}, \quad H_{\rho}(A, B)=\max \left\{\sup _{a \in A} D_{\rho}(a, B), \sup _{b \in B} D_{\rho}(b, A)\right\} .
$$

Let $(X, d)$ be a generalized metric space with $d(x, y):=\left(\begin{array}{c}d_{1}(x, y) \\ \cdots \\ d_{m}(x, y)\end{array}\right)$.

Notice that $d$ is a generalized metric on $X$ if and only if $d_{i}$ are metrics on $X$ for each $i \in\{1,2, \ldots, m\}$.

We denote by

$$
D(A, B):=\left(\begin{array}{c}
D_{d_{1}}(A, B) \\
\cdots \\
D_{d_{m}}(A, B)
\end{array}\right), \quad \text { the generalized gap functional on } P(X)
$$

and by

$$
H(A, B):=\left(\begin{array}{c}
H_{d_{1}}(A, B) \\
\cdots \\
H_{d_{m}}(A, B)
\end{array}\right), \quad \text { the generalized Pompeiu-Hausdorff functional on } P(X) .
$$

It is well known that if $d_{i}$ is a metric on $X, x \in X$ and $Y \in P(X)$, then $D_{d_{i}}(x, Y)=0$ if and only if $x \in \bar{Y}^{d_{i}}$, where $\bar{Y}^{d_{i}}$ denotes the closure of $Y$ in $\left(X, d_{i}\right)$. As a consequence,

$$
\bar{Y}^{d_{i}}=\left\{x \in X: D_{d_{i}}(x, Y)=0\right\} .
$$

Hence, $x \in \bar{Y}^{d_{i}}$ for each $i \in\{1,2, \ldots, m\}$ is equivalent with $D_{d_{i}}(x, Y)=0$ for each $i \in$ $\{1,2, \ldots, m\}$, which is also equivalent with $D(x, Y)=O$. 
Since $\bar{Y}^{d}=\{x \in X: D(x, Y)=O\}$, we have:

(a) $x \in \bar{Y}^{d} \Leftrightarrow x \in \bar{Y}^{d_{i}}$ for each $i \in\{1,2, \ldots, m\}$.

(b) $Y$ is closed with respect to $d \Leftrightarrow Y$ is closed with respect to each $d_{i}$ for $i \in\{1,2, \ldots, m\}$.

We denote by $P_{\mathrm{cl}}(X)$ the set of all nonempty closed (with respect to $d$ ) subsets of $X$.

We have the following two auxiliary results.

Lemma 2.9 Let $(X, d)$ be a generalized metric space, let $x \in X$, and let $Y \in P_{\mathrm{cl}}(X)$. Then,

$x \in Y \quad$ if and only if $\quad D(x, Y)=O$.

Lemma 2.10 Let $(X, d)$ be a generalized metric space, $Y, Z \in P(X), q>1$. Then, for any $y \in Y$, there exists $z \in Z$ such that

$$
d(y, z) \leq q H(Y, Z)
$$

If $(X, d)$ is a nonempty set, and $F: X \rightarrow P(X)$ is a multivalued operator, then the graph of the operator $F$ is denoted by

$$
\operatorname{Graph}(F):=\{(x, y) \in X \times X: y \in F(x)\}
$$

while the fixed point set and, respectively, the strict fixed point set of $F$ are denoted by the symbols

$$
\operatorname{Fix}(F):=\{x \in X: x \in F(x)\}, \quad \text { respectively } \operatorname{SFix}(F):=\{x \in X: F(x)=\{x\}\}
$$

We will present now an extension of the Nadler fixed point theorem in a space endowed with a vector-valued metric, which is also a multivalued version of Perov's theorem.

Theorem 2.11 Let $(X, d)$ be a generalized complete metric space, and let $F: X \rightarrow P_{\mathrm{cl}}(X)$ be a multivalued almost contraction with matrices $A$ and $B$, i.e., there exists two matrices $A, B \in M_{m m}\left(\mathbb{R}_{+}\right)$such that $A$ converges to zero and

$$
H(F(x), F(y)) \leq A d(x, y)+B D(y, F(x)), \quad \text { for all } x, y \in X
$$

Then

(i) $\operatorname{Fix}(F) \neq \varnothing$;

(ii) for each $(x, y) \in \operatorname{Graph}(F)$, there exists a sequence $\left(x_{n}\right)_{n \in \mathbb{N}}$ (with $x_{0}=x, x_{1}=y$ and $x_{n+1} \in F\left(x_{n}\right)$ for each $\left.n \in \mathbb{N}^{*}\right)$ such that $\left(x_{n}\right)_{n \in \mathbb{N}}$ is convergent to a fixed point $x^{*}:=x^{*}(x, y)$ of $F$, and the following relations hold

$$
d\left(x_{n}, x^{*}\right) \leq A^{n}(I-A)^{-1} d\left(x_{0}, x_{1}\right), \quad \text { for each } n \in \mathbb{N}^{*}
$$

and

$$
d\left(x, x^{*}\right) \leq(I-A)^{-1} d(x, y)
$$


Proof Let $x_{0} \in X$ and $x_{1} \in F\left(x_{0}\right)$ be arbitrarily chosen. Let $q \in(1, Q)$, where $Q$ is defined by Theorem 1.2. Then, by Lemma 2.10 , there exists $x_{2} \in F\left(x_{1}\right)$ such that

$$
d\left(x_{1}, x_{2}\right) \leq q H\left(F\left(x_{0}\right), F\left(x_{1}\right)\right) \leq q\left(A d\left(x_{0}, x_{1}\right)+B D\left(x_{1}, F\left(x_{0}\right)\right)\right)=q A d\left(x_{0}, x_{1}\right) .
$$

Inductively, there exists $x_{n+1} \in F\left(x_{n}\right)$ such that

$$
d\left(x_{n}, x_{n+1}\right) \leq(q A)^{n} d\left(x_{0}, x_{1}\right), \quad \text { for any } n \in \mathbb{N}^{*} .
$$

We have

$$
\begin{aligned}
d\left(x_{n}, x_{n+p}\right) & \leq d\left(x_{n}, x_{n+1}\right)+\cdots+d\left(x_{n+p-1}, x_{n+p}\right) \\
& \leq(q A)^{n} d\left(x_{0}, x_{1}\right)+\cdots+(q A)^{n+p-1} d\left(x_{0}, x_{1}\right) \\
& \leq(q A)^{n}\left[I+q A+\cdots+(q A)^{p-1}+\cdots\right] d\left(x_{0}, x_{1}\right) \\
& =(q A)^{n}(I-q A)^{-1} d\left(x_{0}, x_{1}\right) .
\end{aligned}
$$

Thus

$$
d\left(x_{n}, x_{n+p}\right) \leq(q A)^{n}(I-q A)^{-1} d\left(x_{0}, x_{1}\right), \quad \text { for } n \in \mathbb{N}^{*} \text { and } p \in \mathbb{N}^{*} .
$$

Letting $n \rightarrow \infty$, we get that $\left(x_{n}\right)$ is a Cauchy sequence in $X$. Since $(X, d)$ is complete, it follows that there exists $x^{*} \in X$ such that $x_{n} \stackrel{d}{\longrightarrow} x^{*}, n \rightarrow \infty$. Thus,

$$
\begin{aligned}
D\left(x^{*}, F\left(x^{*}\right)\right) & =\left(\begin{array}{c}
D_{1}\left(x^{*}, F\left(x^{*}\right)\right) \\
\ldots \\
D_{m}\left(x^{*}, F\left(x^{*}\right)\right)
\end{array}\right) \\
& \leq\left(\begin{array}{c}
d_{1}\left(x^{*}, x_{n+1}\right)+D_{1}\left(x_{n+1}, F\left(x^{*}\right)\right) \\
\ldots \\
d_{m}\left(x^{*}, x_{n+1}\right)+D_{m}\left(x_{n+1}, F\left(x^{*}\right)\right)
\end{array}\right) \\
& \leq\left(\begin{array}{c}
d_{1}\left(x^{*}, x_{n+1}\right)+H_{1}\left(F\left(x_{n}\right), F\left(x^{*}\right)\right) \\
\ldots \\
d_{m}\left(x^{*}, x_{n+1}\right)+H_{m}\left(F\left(x_{n}\right), F\left(x^{*}\right)\right)
\end{array}\right) \\
& =d\left(x^{*}, x_{n+1}\right)+H\left(F\left(x_{n}\right), F\left(x^{*}\right)\right) \\
& \leq d\left(x^{*}, x_{n+1}\right)+A d\left(x_{n}, x^{*}\right)+B D\left(x^{*}, F\left(x_{n}\right)\right) \\
& \leq d\left(x^{*}, x_{n+1}\right)+A d\left(x_{n}, x^{*}\right)+B\left(d\left(x^{*}, x_{n+1}\right)+D\left(x_{n+1}, F\left(x_{n}\right)\right)\right) \\
& =d\left(x^{*}, x_{n+1}\right)+A d\left(x_{n}, x^{*}\right)+B d\left(x^{*}, x_{n+1}\right) .
\end{aligned}
$$

Letting $n \rightarrow \infty$, we get that $D\left(x^{*}, F\left(x^{*}\right)\right)=O$. By Lemma 2.9, we get that $x^{*} \in F\left(x^{*}\right)$. Moreover, letting $p \rightarrow \infty$ in (7), we obtain

$$
d\left(x_{n}, x^{*}\right) \leq(q A)^{n}(I-q A)^{-1} d\left(x_{0}, x_{1}\right), \quad \text { for any } n \in \mathbb{N}^{*} .
$$


Thus,

$$
\begin{aligned}
d\left(x_{0}, x^{*}\right) & \leq d\left(x_{0}, x_{1}\right)+d\left(x_{1}, x^{*}\right) \\
& \leq d\left(x_{0}, x_{1}\right)+q A(I-q A)^{-1} d\left(x_{0}, x_{1}\right) \\
& =\left[I+q A(I-q A)^{-1}\right] d\left(x_{0}, x_{1}\right) \\
& =\left[I+q A\left(I+q A+\cdots+(q A)^{n}+\cdots\right)\right] d\left(x_{0}, x_{1}\right) \\
& =(I-q A)^{-1} d\left(x_{0}, x_{1}\right) .
\end{aligned}
$$

Letting $q \searrow 1$, we get that $d\left(x_{0}, x^{*}\right) \leq(I-A)^{-1} d\left(x_{0}, x_{1}\right)$.

For the following notions see Rus et al. [34] and A. Petruşel [10].

Definition 2.12 Let $(X, d)$ be a generalized metric space, and let $F: X \rightarrow P_{\mathrm{cl}}(X)$ be a multivalued operator. By definition, $F$ is a multivalued weakly Picard (briefly MWP) operator if for each $(x, y) \in \operatorname{Graph}(F)$, there exists a sequence $\left(x_{n}\right)_{n \in \mathbb{N}}$ such that

(i) $x_{0}=x, x_{1}=y$;

(ii) $x_{n+1} \in F\left(x_{n}\right)$, for each $n \in \mathbb{N}$;

(iii) the sequence $\left(x_{n}\right)_{n \in \mathbb{N}}$ is convergent, and its limit is a fixed point of $F$.

Remark 2.13 A sequence $\left(x_{n}\right)_{n \in \mathbb{N}}$ satisfying the condition (i) and (ii) in the definition above is called a sequence of successive approximations of $F$ starting from $(x, y) \in$ $\operatorname{Graph}(F)$.

If $F: X \rightarrow P(X)$ is an MWP operator, then we define $F^{\infty}: \operatorname{Graph}(F) \rightarrow P(\operatorname{Fix}(F))$ by the formula $F^{\infty}(x, y):=\{z \in \operatorname{Fix}(F) \mid$ there exists a sequence of successive approximations of $F$ starting from $(x, y)$ that converges to $z$.

Definition 2.14 Let $(X, d)$ be a generalized metric space, and let $F: X \rightarrow P(X)$ be an MWP operator. Then, $F$ is called a $\psi$-multivalued weakly Picard operator (briefly $\psi$-MWP operator) if and only if $\psi: \mathbb{R}_{+}^{m} \rightarrow \mathbb{R}_{+}^{m}$ is an increasing operator, continuous in $O$ with $\psi(O)=O$, and there exists a selection $f^{\infty}$ of $F^{\infty}$ such that

$$
d\left(x, f^{\infty}(x, y)\right) \leq \psi(d(x, y)), \quad \text { for all }(x, y) \in \operatorname{Graph}(F) .
$$

Example 2.15 Let $(X, d)$ be a generalized complete metric space, and let $F: X \rightarrow P_{\mathrm{cl}}(X)$ be a multivalued almost contraction with matrices $A$ and $B$. Then, by Theorem 2.11 (see (i) and (ii)), we get that $F$ is a $(I-A)^{-1}$-MWP operator.

Two important stability concepts are given now.

Definition 2.16 Let $(X, d)$ be a generalized metric space, and let $F: X \rightarrow P(X)$ be a multivalued operator. The fixed point inclusion

$$
x \in F(x), \quad x \in X
$$


is called generalized Ulam-Hyers stable if and only if there exists $\psi: \mathbb{R}_{+}^{m} \rightarrow \mathbb{R}_{+}^{m}$ increasing, continuous in $O$ with $\psi(O)=O$ such that for each $\varepsilon:=\left(\varepsilon_{1}, \ldots, \varepsilon_{m}\right)$ (with $\varepsilon_{i}>0$ for $i \in\{1, \ldots, m\})$ and for each $\varepsilon$-solution $y^{*} \in X$ of (8), i.e.,

$$
D\left(y^{*}, F\left(y^{*}\right)\right) \leq \varepsilon,
$$

there exists a solution $x^{*}$ of the fixed point inclusion (8) such that

$$
d\left(y^{*}, x^{*}\right) \leq \psi(\varepsilon) .
$$

In particular, if $\psi(t)=C \cdot t$ for each $t \in \mathbb{R}_{+}^{m}$ (where $C \in M_{m m}\left(\mathbb{R}_{+}\right)$), then the fixed point inclusion (8) is said to be Ulam-Hyers stable.

Definition 2.17 Let $(X, d)$ be a generalized metric space, and let $F: X \rightarrow P(X)$ be a multivalued operator. Then, the multivalued operator $F$ is said to have the limit shadowing property if for each sequence $\left(y_{n}\right)_{n \in \mathbb{N}}$ in $X$ such that $D\left(y_{n+1}, F\left(y_{n}\right)\right) \rightarrow O$ as $n \rightarrow+\infty$, there exists a sequence $\left(x_{n}\right)_{n \in \mathbb{N}}$ of successive approximations of $F$ such that $d\left(x_{n}, y_{n}\right) \rightarrow O$ as $n \rightarrow+\infty$

An auxiliary result is as follows.

Cauchy-type lemma Let $A \in M_{m m}\left(\mathbb{R}_{+}\right)$be a matrix convergent toward zero and $\left(B_{n}\right)_{n \in \mathbb{N}} \in$ $\mathbb{R}_{+}^{m}$ be a sequence such that $\lim _{n \rightarrow+\infty} B_{n}=O$. Then

$$
\lim _{n \rightarrow+\infty}\left(\sum_{k=0}^{n} A^{n-k} B_{k}\right)=O .
$$

We can prove now the Ulam-Hyers stability of the fixed point inclusion (8) for the case of a multivalued contraction, which has at least one strict fixed point. The limit shadowing property is also established.

Theorem 2.18 Let $(X, d)$ be a generalized complete metric space, and let $F: X \rightarrow P_{\mathrm{cl}}(X)$ be a multivalued $A$-contraction, i.e., there exists a matrix $A \in M_{m m}\left(\mathbb{R}_{+}\right)$such that $A$ converges to zero and

$$
H(F(x), F(y)) \leq A d(x, y), \quad \text { for all } x, y \in X .
$$

Suppose also that SFix $(F) \neq \emptyset$, i.e., there exists $x^{*} \in X$ such that $\left\{x^{*}\right\}=F\left(x^{*}\right)$. Then

(a) the fixed point inclusion (8) is Ulam-Hyers stable;

(b) the multivalued operator $F$ has the limit shadowing property.

Proof (a) Let $\varepsilon:=\left(\varepsilon_{1}, \ldots, \varepsilon_{m}\right)$ (with $\varepsilon_{i}>0$ for $i \in\{1, \ldots, m\}$ ), and let $y^{*} \in X$ be an $\varepsilon$-solution of $(8)$, i.e., $D\left(y^{*}, F\left(y^{*}\right)\right) \leq \varepsilon$. Let $x^{*} \in X$ be such that $\left\{x^{*}\right\}=F\left(x^{*}\right)$. Then

$$
d\left(y^{*}, x^{*}\right) \leq D\left(y^{*}, F\left(y^{*}\right)\right)+H\left(F\left(y^{*}\right), F\left(x^{*}\right)\right) \leq \varepsilon+A d\left(y^{*}, x^{*}\right) .
$$

Thus $d\left(y^{*}, x^{*}\right) \leq(I-A)^{-1} \varepsilon$. 
(b) Let $\left(y_{n}\right)_{n \in \mathbb{N}}$ be a sequence in $X$ such that $D\left(y_{n+1}, F\left(y_{n}\right)\right) \rightarrow O$ as $n \rightarrow \infty$. We shall prove first that $d\left(y_{n}, x^{*}\right) \rightarrow O$ as $n \rightarrow+\infty$. We successively have

$$
\begin{aligned}
d\left(x^{*}, y_{n+1}\right) & \leq H\left(x^{*}, F\left(y_{n}\right)\right)+D\left(y_{n+1}, F\left(y_{n}\right)\right) \leq A d\left(x^{*}, y_{n}\right)+D\left(y_{n+1}, F\left(y_{n}\right)\right) \\
& \leq A\left[A d\left(x^{*}, y_{n-1}\right)+D\left(y_{n}, F\left(y_{n-1}\right)\right)\right]+D\left(y_{n+1}, F\left(y_{n}\right)\right) \leq \cdots \\
& \leq A^{n+1} d\left(x^{*}, y_{0}\right)+A^{n} D\left(y_{1}, F\left(y_{0}\right)\right)+\cdots+A D\left(y_{n}, F\left(y_{n-1}\right)\right)+D\left(y_{n+1}, F\left(y_{n}\right)\right) .
\end{aligned}
$$

By Cauchy's lemma, the right hand side tends to $O$ as $n \rightarrow+\infty$. Thus $d\left(x^{*}, y_{n+1}\right) \rightarrow O$ as $n \rightarrow+\infty$.

On the other hand, by Theorem 2.11(i)-(ii), we know that there exists a sequence $\left(x_{n}\right)_{n \in \mathbb{N}}$ of successive approximations for $F$ starting from arbitrary $\left(x_{0}, x_{1}\right) \in \operatorname{Graph}(F)$, which converge to a fixed point $x^{*} \in X$ of the operator $F$. Since, the fixed point is unique, we get that $d\left(x_{n}, x^{*}\right) \rightarrow O$ as $n \rightarrow+\infty$. Hence, for such a sequence $\left(x_{n}\right)_{n \in \mathbb{N}}$, we have

$$
d\left(y_{n}, x_{n}\right) \leq d\left(y_{n}, x^{*}\right)+d\left(x^{*}, x_{n}\right) \rightarrow O \quad \text { as } n \rightarrow+\infty .
$$

We also have the following abstract results concerning the Ulam-Hyers stability of the fixed point inclusion (8) for multivalued operators.

Theorem 2.19 Let $(X, d)$ be a generalized metric space, and let $F: X \rightarrow P_{\mathrm{cl}}(X)$ be a multivalued $\psi$-weakly Picard operator. Suppose also that there exists a matrix $C \in \mathbb{M}_{m m}\left(\mathbb{R}_{+}\right)$ such that for any $\varepsilon:=\left(\varepsilon_{1}, \ldots, \varepsilon_{m}\right)$ (with $\varepsilon_{i}>0$ for $\left.i \in\{1, \ldots, m\}\right)$ and any $z \in X$ with $D(z, F(z)) \leq \varepsilon$ there exists $u \in F(z)$ such that $d(z, u) \leq C \varepsilon$. Then, the fixed point inclusion (8) is generalized Ulam-Hyers stable.

Proof Let $\varepsilon:=\left(\varepsilon_{1}, \ldots, \varepsilon_{m}\right)$ (with $\varepsilon_{i}>0$ for $\left.i \in\{1, \ldots, m\}\right)$ and $y^{*} \in X$ be a $\varepsilon$-solution of (8), i.e., $D\left(y^{*}, F\left(y^{*}\right)\right) \leq \varepsilon$. Since $F$ is a multivalued $\psi$-weakly Picard operator, for each $(x, y) \in$ $\operatorname{Graph}(F)$, we have

$$
d\left(x, f^{\infty}(x, y)\right) \leq \psi(d(x, y)) .
$$

Now, by our additional assumption, for $y^{*} \in X$ there exists $u^{*} \in F\left(y^{*}\right)$ such that $d\left(y^{*}\right.$, $\left.u^{*}\right) \leq C \varepsilon$. Thus, define $x^{*}:=f^{\infty}\left(y^{*}, u^{*}\right) \in \operatorname{Fix}(F)$, and we get

$$
d\left(y^{*}, x^{*}\right) \leq \psi\left(d\left(y^{*}, u^{*}\right)\right) \leq \psi(C \varepsilon) .
$$

As an exemplification of the previous theorem, we have the following result.

Let us recall first an important notion. A subset $U$ of a (generalized) metric space $(X, d)$ is called proximinal if for each $x \in X$ there exists $u \in U$ such that $d(x, y)=D(x, U)$.

As a consequence of Theorem 2.11 and of the abstract result above, we obtain the following theorem.

Corollary 2.20 Let $(X, d)$ be a generalized complete metric space, and let $F: X \rightarrow P_{\mathrm{cl}}(X)$ be a multivalued A-contraction with proximinal values. Then the fixed point inclusion (8) is Ulam-Hyers stable. 
Proof Let $\varepsilon:=\left(\varepsilon_{1}, \ldots, \varepsilon_{m}\right)$ (with $\varepsilon_{i}>0$ for $\left.i \in\{1, \ldots, m\}\right)$, and let $y^{*} \in X$ be a $\varepsilon$-solution of (8), i.e., $D\left(y^{*}, F\left(y^{*}\right)\right) \leq \varepsilon$. Since $F$ is an $(I-A)^{-1}$-MWP operator, for each $(x, y) \in \operatorname{Graph}(F)$, we have

$$
d\left(x, f^{\infty}(x, y)\right) \leq(I-A)^{-1} d(x, y) .
$$

Since $F\left(y^{*}\right)$ is a proximinal set, there exists $u^{*} \in F\left(y^{*}\right)$ such that $d\left(y^{*}, u^{*}\right)=D\left(y^{*}, F\left(y^{*}\right)\right)$. Thus, if we consider $x^{*}:=f^{\infty}\left(y^{*}, u^{*}\right) \in \operatorname{Fix}(F)$, we get

$$
d\left(y^{*}, x^{*}\right) \leq(I-A)^{-1} d\left(y^{*}, u^{*}\right) \leq(I-A)^{-1} \varepsilon .
$$

Remark 2.21 It is an open question to give other examples of how Theorem 2.19 can be applied. A more general open question is to give similar results for multivalued almost contractions with matrices $A$ and $B$.

For other examples and results regarding the Ulam-Hyers stability and the limit shadowing property of the operatorial equations and inclusions, see Bota-Petruşel [35], PetruPetruşel-Yao [36], Petruşel-Rus [29] and Rus [32, 33].

\section{An application to coupled fixed point results for singlevalued operators without mixed monotone property}

Let $X$ be a nonempty set endowed with a partial order relation denoted by $\leq$. Then we denote

$$
X_{\leq}:=\left\{\left(x_{1}, x_{2}\right) \in X \times X: x_{1} \leq x_{2} \text { or } x_{2} \leq x_{1}\right\} .
$$

If $f: X \rightarrow X$ is an operator, then we denote the Cartesian product of $f$ with itself as follows

$$
f \times f: X \times X \rightarrow X \times X, \quad \text { given by }(f \times f)\left(x_{1}, x_{2}\right):=\left(f\left(x_{1}\right), f\left(x_{2}\right)\right) \text {. }
$$

Definition 3.1 Let $X$ be a nonempty set. Then $(X, d, \leq)$ is called an ordered generalized metric space if

(i) $(X, d)$ is a generalized metric space in the sense of Perov;

(ii) $(X, \leq)$ is a partially ordered set.

The following result will be an important tool in our approach.

Theorem 3.2 Let $(X, d, \leq)$ be an ordered generalized metric space, and let $f: X \rightarrow X$ be an operator. We suppose that

(1) for each $(x, y) \notin X_{\leq}$there exists $z(x, y):=z \in X$ such that $(x, z),(y, z) \in X_{\leq}$;

(2) $X_{\leq} \in I(f \times f)$;

(3) $f:(X, d) \rightarrow(X, d)$ is continuous;

(4) the metric $d$ is complete;

(5) there exists $x_{0} \in X$ such that $\left(x_{0}, f\left(x_{0}\right)\right) \in X_{\leq}$;

(6) there exists a matrix $A \in M_{m m}\left(\mathbb{R}_{+}\right)$, which converges to zero such that

$$
d(f(x), f(y)) \leq \operatorname{Ad}(x, y) \quad \text { for each }(x, y) \in X_{\leq} .
$$

Then $f:(X, d) \rightarrow(X, d)$ is a Picard operator. 
Proof Let $x \in X$ be arbitrary. Since $\left(x_{0}, f\left(x_{0}\right)\right) \in X_{\leq}$, by (6) and (4), we get that there exists $x^{*} \in X$ such that $\left(f^{n}\left(x_{0}\right)\right)_{n \in \mathbb{N}} \rightarrow x^{*}$ as $n \rightarrow+\infty$. By (3), we get that $x^{*} \in \operatorname{Fix}(f)$.

If $\left(x, x_{0}\right) \in X_{\leq}$, then by (2), we have that $\left(f^{n}(x), f^{n}\left(x_{0}\right)\right) \in X_{\leq}$for each $n \in \mathbb{N}$. Thus, by (6), we get that $\left(f^{n}(x)\right)_{n \in \mathbb{N}} \rightarrow x^{*}$ as $n \rightarrow+\infty$.

If $\left(x, x_{0}\right) \notin X_{\leq}$, then by (1), it follows that there exists $z\left(x, x_{0}\right):=z \in X_{\leq}$such that $(x, z),\left(x_{0}, z\right) \in X_{\leq}$. By the fact that $\left(x_{0}, z\right) \in X_{\leq}$, as before, we get that $\left(f^{n}(z)\right)_{n \in \mathbb{N}} \rightarrow x^{*}$ as $n \rightarrow+\infty$. This together with the fact that $(x, z) \in X_{\leq}$implies that $\left(f^{n}(x)\right)_{n \in \mathbb{N}} \rightarrow x^{*}$ as $n \rightarrow+\infty$.

Finally, the uniqueness of the fixed point follows by the contraction condition (6) using again the assumption (1).

Remark 3.3 The conclusion of the theorem above holds if instead of hypothesis (2) we put

$\left(2^{\prime}\right) f:(X, \leq) \rightarrow(X, \leq)$ is monotone increasing

or

$\left(2^{\prime \prime}\right) f:(X, \leq) \rightarrow(X, \leq)$ is monotone decreasing.

Of course, it is easy to remark that assertion (2) in Theorem 3.2 is more general. For example, if we consider the ordered metric space $\left(\mathbb{R}^{2}, d, \leq\right)$, then $f: \mathbb{R}^{2} \rightarrow \mathbb{R}^{2}, f\left(x_{1}, x_{2}\right):=$ $\left(g\left(x_{1}, x_{2}\right), g\left(x_{1}, x_{2}\right)\right)$ satisfies (2) for any $g: \mathbb{R}^{2} \rightarrow \mathbb{R}$.

Remark 3.4 Condition (5) from the theorem above is equivalent with

(5') $f$ has a lower or an upper fixed point in $X$.

Remark 3.5 For some similar results, see Theorem 4.2 and Theorem 4.7 in [37].

We will apply the above result for the coupled fixed point problem generated by two operators.

Let $X$ be a nonempty set endowed with a partial order relation denoted by $\leq$. If we consider $z:=(x, y), w:=(u, v)$ two arbitrary elements of $Z:=X \times X$, then, by definition,

$$
z \preceq w \quad \text { if and only if } \quad(x \geq u \text { and } y \leq v) .
$$

Notice that $\preceq$ is a partial order relation on $Z$.

We denote

$$
Z_{\preceq}=\{(z, w):=((x, y),(u, v)) \in Z \times Z: z \preceq w \text { or } w \preceq z\} .
$$

Let $T: Z \rightarrow Z$ be an operator defined by

$$
T(x, y):=\left(\begin{array}{l}
T_{1}(x, y) \\
T_{2}(x, y)
\end{array}\right)=\left(T_{1}(x, y), T_{2}(x, y)\right) .
$$

The Cartesian product of $T$ and $T$ will be denoted by $T \times T$, and it is defined in the following way

$$
T \times T: Z \times Z \rightarrow Z \times Z, \quad(T \times T)(z, w):=(T(z), T(w)) .
$$


The first main result of this section is the following theorem.

Theorem 3.6 Let $(X, d, \leq)$ be an ordered and complete metric space, and let $T_{1}, T_{2}: X \times$ $X \rightarrow X$ be two operators. We suppose that

(i) for each $z=(x, y), w=(u, v) \in X \times X$, which are not comparable with respect to the partial ordering $\preceq$ on $X \times X$, there exists $t:=\left(t_{1}, t_{2}\right) \in X \times X$ (which may depend on $(x, y)$ and $(u, v))$ such that $t$ is comparable (with respect to the partial ordering $\preceq$ ) with both $z$ and w, i.e.,

$$
\begin{aligned}
& \left(\left(x \geq t_{1} \text { and } y \leq t_{2}\right) \text { or }\left(x \leq t_{1} \text { and } y \geq t_{2}\right)\right) \quad \text { and } \\
& \left(\left(u \geq t_{1} \text { and } v \leq t_{2}\right) \text { or }\left(u \leq t_{1} \text { and } v \geq t_{2}\right)\right)
\end{aligned}
$$

(ii) for all ( $x \geq u$ and $y \leq v)$ or ( $u \geq x$ and $v \leq y)$, we have

$$
\left\{\begin{array} { l } 
{ T _ { 1 } ( x , y ) \geq T _ { 1 } ( u , v ) , } \\
{ T _ { 2 } ( x , y ) \leq T _ { 2 } ( u , v ) }
\end{array} \text { or } \quad \left\{\begin{array}{l}
T_{1}(u, v) \geq T_{1}(x, y) \\
T_{2}(u, v) \leq T_{2}(x, y)
\end{array}\right.\right.
$$

(iii) $T_{1}, T_{2}: X \times X \rightarrow X$ are continuous;

(iv) there exists $z_{0}:=\left(z_{0}^{1}, z_{0}^{2}\right) \in X \times X$ such that

$$
\left\{\begin{array} { l } 
{ z _ { 0 } ^ { 1 } \geq T _ { 1 } ( z _ { 0 } ^ { 1 } , z _ { 0 } ^ { 2 } ) , } \\
{ z _ { 0 } ^ { 2 } \leq T _ { 2 } ( z _ { 0 } ^ { 1 } , z _ { 0 } ^ { 2 } ) }
\end{array} \quad \text { or } \quad \left\{\begin{array}{l}
T_{1}\left(z_{0}^{1}, z_{0}^{2}\right) \geq z_{0}^{1} \\
T_{2}\left(z_{0}^{1}, z_{0}^{2}\right) \leq z_{0}^{2}
\end{array}\right.\right.
$$

(v) there exists a matrix $A=\left(\begin{array}{ll}k_{1} & k_{2} \\ k_{3} & k_{4}\end{array}\right) \in M_{2}\left(\mathbb{R}_{+}\right)$convergent toward zero such that

$$
\begin{aligned}
& d\left(T_{1}(x, y), T_{1}(u, v)\right) \leq k_{1} d(x, u)+k_{2} d(y, v), \\
& d\left(T_{2}(x, y), T_{2}(u, v)\right) \leq k_{3} d(x, u)+k_{4} d(y, v)
\end{aligned}
$$

for all ( $x \geq u$ and $y \leq v)$ or $(u \geq x$ and $v \leq y)$.

Then there exists a unique element $\left(x^{*}, y^{*}\right) \in X \times X$ such that

$$
x^{*}=T_{1}\left(x^{*}, y^{*}\right) \text { and } y^{*}=T_{2}\left(x^{*}, y^{*}\right)
$$

and the sequence of the successive approximations $\left(T_{1}^{n}\left(w_{0}^{1}, w_{0}^{2}\right), T_{2}^{n}\left(w_{0}^{1}, w_{0}^{2}\right)\right)$ converges to $\left(x^{*}, y^{*}\right)$ as $n \rightarrow \infty$ for all $w_{0}=\left(w_{0}^{1}, w_{0}^{2}\right) \in X \times X$.

Proof Denote $Z:=X \times X$. We show that Theorem 3.2 is applicable for the operator $T$ : $Z \rightarrow Z$ defined by

$$
T(x, y):=\left(T_{1}(x, y), T_{2}(x, y)\right) .
$$

Notice first that by (i), we get that if $(z:=(x, y), w:=(u, v)) \notin Z_{\leq}$, there exists $t \in Z$ such that $(z, t),(w, t) \in Z_{\preceq}$. Thus, the first assumption of Theorem 3.2 holds. 
In order to prove (2) from Theorem 3.2, let $z=(x, y), w=(u, v)$ be arbitrary elements of $Z_{\leq}($where $(x \geq u$ and $y \leq v)$ or $(u \geq x$ and $v \leq y))$ such that

$$
\left\{\begin{array} { l } 
{ T _ { 1 } ( x , y ) \geq T _ { 1 } ( u , v ) , } \\
{ T _ { 2 } ( x , y ) \leq T _ { 2 } ( u , v ) }
\end{array} \text { or } \quad \left\{\begin{array}{l}
T_{1}(u, v) \geq T_{1}(x, y), \\
T_{2}(u, v) \leq T_{2}(x, y) .
\end{array}\right.\right.
$$

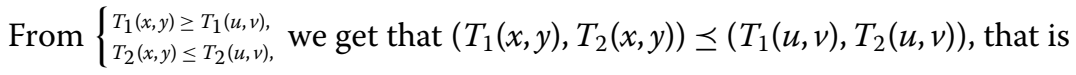

$$
T(z) \preceq T(w) .
$$

By a similar approach, we alternatively have that

$$
T(w) \preceq T(z) .
$$

Using (11) and (12), we get that

$$
(T(z), T(w)) \in Z_{\preceq} \quad \text { for all }(z, w) \in Z_{\preceq} .
$$

Thus, we get $(T \times T)\left(Z_{\preceq}\right) \subseteq Z_{\preceq}$, which implies that

$$
Z_{\leq} \in I(T \times T) .
$$

In order to obtain (5) from Theorem 3.2, notice first that since there exists $\left(z_{0}^{1}, z_{0}^{2}\right) \in$ $X \times X$ such that

$$
\left\{\begin{array} { l } 
{ z _ { 0 } ^ { 1 } \geq T _ { 1 } ( z _ { 0 } ^ { 1 } , z _ { 0 } ^ { 2 } ) , } \\
{ z _ { 0 } ^ { 2 } \leq T _ { 2 } ( z _ { 0 } ^ { 1 } , z _ { 0 } ^ { 2 } ) }
\end{array} \text { or } \quad \left\{\begin{array}{l}
T_{1}\left(z_{0}^{1}, z_{0}^{2}\right) \geq z_{0}^{1} \\
T_{2}\left(z_{0}^{1}, z_{0}^{2}\right) \leq z_{0}^{2}
\end{array}\right.\right.
$$

we obtain that

$$
\left(z_{0}^{1}, z_{0}^{2}\right) \preceq\left(T_{1}\left(z_{0}^{1}, z_{0}^{2}\right), T_{2}\left(z_{0}^{1}, z_{0}^{2}\right)\right) .
$$

Thus, we have $z_{0} \preceq T\left(z_{0}\right)$. By a similar approach, we alternatively obtain that $T\left(z_{0}\right) \preceq z_{0}$. Thus, $\left(z_{0}, T\left(z_{0}\right)\right) \in Z_{\leq}$.

Finally, in order to prove hypotheses (3) and (6) from Theorem 3.2, we define the mapping $\tilde{d}: Z \times Z \rightarrow \mathbb{R}_{+}^{2}$ by

$$
\tilde{d}((x, y),(u, v)):=\left(\begin{array}{l}
d(x, u) \\
d(y, v)
\end{array}\right) .
$$

Notice now that if $(X, d, \leq)$ is an ordered metric space, then $(Z, \widetilde{d}, \preceq)$ is an ordered generalized metric space. The completeness of $\tilde{d}$ follows from the completeness of $d$. Notice also that the continuity of $T$ follows by (iii). For hypothesis (6), we successively have

$$
\begin{aligned}
\widetilde{d} & (T(x, y), T(u, v)) \\
& =\widetilde{d}\left(\left(T_{1}(x, y), T_{2}(x, y)\right),\left(T_{1}(u, v), T_{2}(u, v)\right)\right)
\end{aligned}
$$




$$
\begin{aligned}
& =\left(\begin{array}{l}
d\left(T_{1}(x, y), T_{1}(u, v)\right) \\
d\left(T_{2}(x, y), T_{2}(u, v)\right)
\end{array}\right) \\
& \leq\left(\begin{array}{l}
k_{1} d(x, u)+k_{2} d(y, v) \\
k_{3} d(x, u)+k_{4} d(y, v)
\end{array}\right) \\
& =\left(\begin{array}{l}
k_{1} k_{2} \\
k_{3} k_{4}
\end{array}\right)\left(\begin{array}{l}
d(x, u) \\
d(y, v)
\end{array}\right)=A \tilde{d}((x, y),(u, v)) .
\end{aligned}
$$

Hence

$$
\tilde{d}(T(z), T(w)) \leq A \widetilde{d}(z, w) \quad \text { for all } z, w \in Z_{\preceq} .
$$

Thus, the triple $(Z, \widetilde{d}, \preceq)$ and the operator $T: Z \rightarrow Z$ satisfy all the hypothesis of Theorem 3.2. Hence, $T$ is a Picard operator, and so, the equation $z=T(z)$ has a unique solution $z^{*} \in X \times X$, and the sequence of successive approximations of the operator $T$, starting from any $w_{0} \in X \times X$ converges to $z^{*}$. Thus, the unique element $z^{*}=\left(x^{*}, y^{*}\right)$ satisfies the system

$$
\left\{\begin{array}{l}
x^{*}=T_{1}\left(x^{*}, y^{*}\right) \\
y^{*}=T_{2}\left(x^{*}, y^{*}\right)
\end{array}\right.
$$

and $T^{n}\left(w_{0}\right) \rightarrow z^{*}$ as $n \rightarrow \infty$, where $T^{n}\left(w_{0}\right)=\left(T_{1}^{n}\left(w_{0}\right), T_{2}^{n}\left(w_{0}\right)\right)$ and

$$
\begin{aligned}
& T_{1}^{n}\left(w_{0}\right)=T_{1}^{n-1}\left(T_{1}\left(w_{0}\right), T_{2}\left(w_{0}\right)\right), \\
& T_{2}^{n}\left(w_{0}\right)=T_{2}^{n-1}\left(T_{1}\left(w_{0}\right), T_{2}\left(w_{0}\right)\right)
\end{aligned}
$$

for all $n \in \mathbb{N}, n \geq 2$.

For the particular case of classical coupled fixed point problems (i.e., $T_{1}(x, y):=S(x, y)$ and $T_{1}(x, y):=S(y, x)$, where $S: X \times X \rightarrow X$ is a given operator) we get (by Theorem 3.6) the following generalization of the Gnana Bhaskar-Lakshmikantham theorem in [17].

Theorem 3.7 Let $(X, d, \leq)$ be an ordered and complete metric space, and let $S: X \times X \rightarrow X$ be an operator. We suppose that

(i) for each $z=(x, y), w=(u, v) \in X \times X$, which are not comparable with respect to the partial ordering $\preceq$ on $X \times X$, there exists $t:=\left(t_{1}, t_{2}\right) \in X \times X$ (which may depend on $(x, y)$ and $(u, v))$ such that $t$ is comparable (with respect to the partial ordering $\preceq$ ) with both $z$ and $w$;

(ii) for all ( $x \geq u$ and $y \leq v)$ or $(u \geq x$ and $v \leq y)$, we have

$$
\left\{\begin{array} { l } 
{ S ( x , y ) \geq S ( u , v ) , } \\
{ S ( y , x ) \leq S ( v , u ) }
\end{array} \text { or } \quad \left\{\begin{array}{l}
S(u, v) \geq S(x, y) \\
S(v, u) \leq S(y, x)
\end{array}\right.\right.
$$

(iii) $S: X \times X \rightarrow X$ is continuous;

(iv) there exists $z_{0}:=\left(z_{0}^{1}, z_{0}^{2}\right) \in X \times X$ such that

$$
\left\{\begin{array} { l } 
{ z _ { 0 } ^ { 1 } \geq S ( z _ { 0 } ^ { 1 } , z _ { 0 } ^ { 2 } ) , } \\
{ z _ { 0 } ^ { 2 } \leq S ( z _ { 0 } ^ { 2 } , z _ { 0 } ^ { 1 } ) }
\end{array} \quad \text { or } \quad \left\{\begin{array}{l}
S\left(z_{0}^{1}, z_{0}^{2}\right) \geq z_{0}^{1} \\
S\left(z_{0}^{2}, z_{0}^{1}\right) \leq z_{0}^{2}
\end{array}\right.\right.
$$


(v) there exist $k_{1}, k_{2} \in \mathbb{R}_{+}$with $k_{1}+k_{2}<1$ such that

$$
\begin{gathered}
d(S(x, y), S(u, v)) \leq k_{1} d(x, u)+k_{2} d(y, v) \\
\text { for all }(x \geq u \text { and } y \leq v) \text { or }(u \geq x \text { and } v \leq y) .
\end{gathered}
$$

Then there exists a unique element $\left(x^{*}, y^{*}\right) \in X \times X$ such that

$$
x^{*}=S\left(x^{*}, y^{*}\right) \text { and } y^{*}=S\left(y^{*}, x^{*}\right)
$$

and the sequence of the successive approximations $\left(S^{n}\left(w_{0}^{1}, w_{0}^{2}\right), S^{n}\left(w_{0}^{2}, w_{0}^{1}\right)\right)$ converges to $\left(x^{*}, y^{*}\right)$ as $n \rightarrow \infty$ for all $w_{0}=\left(w_{0}^{1}, w_{0}^{2}\right) \in X \times X$.

As an application of the previous theorem, we get now an existence and uniqueness result for a system of functional-integral equations, which appears in some traffic flow models.

$$
\left\{\begin{array}{l}
x(t)=f\left(t, x(t), \int_{0}^{T} k(t, s, x(s), y(s)) d s\right) \\
y(t)=f\left(t, y(t), \int_{0}^{T} k(t, s, x(s), y(s)) d s\right)
\end{array}\right.
$$

By a solution of the previous system, we understand a couple $(x, y) \in C[0, T] \times C[0, T]$, which satisfies the system for all $t \in[0, T]$.

As before, we consider on $X:=C[0, T]$ the following partial ordering relation

$$
x \leq_{C} y \quad \text { if and only if } \quad x(t) \leq y(t) \quad \text { for all } t \in[0, T]
$$

and the supremum norm

$$
\|x\|_{C}:=\max _{t \in[0, T]}|x(t)|
$$

Notice that, as before, the partial ordering relation $\leq_{C}$ generates on $X \times X$ a partial ordering $\preceq_{C}$.

If we define

$$
S: X \times X \rightarrow X,(x, y) \longmapsto S(x, y), \quad \text { where } S(x, y)(t):=f\left(t, x(t), \int_{0}^{T} k(t, s, x(s), y(s)) d s\right)
$$

then, the above system can be represented as a coupled fixed point problem

$$
\left\{\begin{array}{l}
x=S(x, y) \\
y=S(y, x)
\end{array}\right.
$$

An existence and uniqueness result for the system (18) is the following theorem.

Theorem 3.8 Let $k:[0, T] \times[0, T] \times \mathbb{R}^{2} \rightarrow \mathbb{R}$ and $f:[0, T] \times \mathbb{R} \times \mathbb{R} \rightarrow \mathbb{R}$ be two continuous mappings. We suppose that 
(i) there exists $z_{0}:=\left(z_{0}^{1}, z_{0}^{2}\right) \in C[0, T] \times C[0, T]$ such that

$$
\begin{aligned}
& \left\{\begin{array}{l}
z_{0}^{1}(t) \geq f\left(t, z_{0}^{1}(t), \int_{0}^{t} k\left(t, s, z_{0}^{1}(t), z_{0}^{2}(t)\right) d s\right), \\
z_{0}^{2}(t) \leq f\left(t, z_{0}^{2}(t), \int_{0}^{t} k\left(t, s, z_{0}^{2}(t), z_{0}^{1}(t)\right) d s\right)
\end{array}\right. \text { or } \\
& \left\{\begin{array}{l}
z_{0}^{1}(t) \leq f\left(t, z_{0}^{1}(t), \int_{0}^{t} k\left(t, s, z_{0}^{1}(t), z_{0}^{2}(t)\right) d s\right), \\
z_{0}^{2}(t) \geq f\left(t, z_{0}^{2}(t), \int_{0}^{t} k\left(t, s, z_{0}^{2}(t), z_{0}^{1}(t)\right) d s\right) ;
\end{array}\right.
\end{aligned}
$$

(ii) (a) $f(t, \cdot, z)$ is increasing for all $t \in[0, T], z \in \mathbb{R}$ and $k(t, s, \cdot, z)$ is increasing, $k(t, s, w, \cdot)$ is decreasing and $f(t, w, \cdot)$ is increasing for all $t, s \in[0, T], w, z \in \mathbb{R}$ or

(b) $f(t, \cdot, z)$ is decreasing for all $t \in[0, T], z \in \mathbb{R}$ and $k(t, s, \cdot, z)$ is decreasing, $k(t, s, w, \cdot)$ is increasing and $f(t, w, \cdot)$ is decreasing for all $t, s \in[0, T], w, z \in \mathbb{R}$;

(iii) there exist $k_{1}, k_{2} \in \mathbb{R}_{+}$such that

$$
\begin{aligned}
& \qquad\left|f\left(t, w_{1}, z_{1}\right)-f\left(t, w_{2}, z_{2}\right)\right| \leq k_{1}\left|w_{1}-w_{2}\right|+k_{2}\left|z_{1}-z_{2}\right| \\
& \text { for all } t \in[0, T] \text { and } w_{1}, w_{2}, z_{1}, z_{2} \in \mathbb{R} ;
\end{aligned}
$$

(iv) there exist $\alpha, \beta \in \mathbb{R}_{+}$such that for all $t, s \in[0, T]$ and $w_{1}, w_{2}, z_{1}, z_{2} \in \mathbb{R}$, we have

$$
\left|k\left(t, s, w_{1}, z_{1}\right)-k\left(t, s, w_{2}, z_{2}\right)\right| \leq \alpha\left|w_{1}-w_{2}\right|+\beta\left|z_{1}-z_{2}\right|
$$

(v) $k_{1}+k_{2} T(\alpha+\beta)<1$.

Then, there exists a unique solution $\left(x^{*}, y^{*}\right)$ of system (18).

Proof From the hypotheses, we get that all the assumptions of Theorem 3.7 are satisfied for the operator

$$
S: X \times X \rightarrow X, \quad(x, y) \longmapsto S(x, y), \quad S(x, y)(t):=f\left(t, x(t), \int_{0}^{T} k(t, s, x(s), y(s)) d s\right),
$$

where $X:=\left(C[0, T], \leq_{C},\|\cdot\|_{C}\right)$.

We introduce now the concept of Ulam-Hyers stability for coupled fixed point problems.

Definition 3.9 Let $(X, d)$ be a metric space, and let $T_{1}, T_{2}: X \times X \rightarrow X$ be two operators. Then the operatorial equations system

$$
\left\{\begin{array}{l}
x=T_{1}(x, y), \\
y=T_{2}(x, y)
\end{array}\right.
$$

is said to be Ulam-Hyers stable if there exist $c_{1}, c_{2}, c_{3}, c_{4}>0$ such that for each $\varepsilon_{1}, \varepsilon_{2}>0$ and each pair $\left(u^{*}, v^{*}\right) \in X \times X$ such that

$$
\begin{aligned}
& d\left(u^{*}, T_{1}\left(u^{*}, v^{*}\right)\right) \leq \varepsilon_{1}, \\
& d\left(v^{*}, T_{2}\left(u^{*}, v^{*}\right)\right) \leq \varepsilon_{2}
\end{aligned}
$$


there exists a solution $\left(x^{*}, y^{*}\right) \in X \times X$ of (19) such that

$$
\begin{aligned}
& d\left(u^{*}, x^{*}\right) \leq c_{1} \varepsilon_{1}+c_{2} \varepsilon_{2}, \\
& d\left(v^{*}, y^{*}\right) \leq c_{3} \varepsilon_{1}+c_{4} \varepsilon_{2} .
\end{aligned}
$$

It is an open problem to obtain Ulam-Hyers stability results for the coupled fixed point problem in the context of ordered metric spaces. For several results on this subject, see $[35,36]$.

Remark 3.10 The case of a system of operatorial inclusions of the form

$$
\left\{\begin{array}{l}
x \in T_{1}(x, y), \\
y \in T_{2}(x, y)
\end{array}\right.
$$

(where $T_{1}, T_{2}: X \times X \rightarrow P(X)$ are two given multivalued operators) can be treated in a similar way.

\section{Competing interests}

The authors declare that they have no competing interests.

\section{Authors' contributions}

The authors declare that the first two authors on one hand and the third author on the other hand have equal contributions to this paper. All authors read and approved the final manuscript.

\section{Acknowledgements}

(1) For the first author, this paper was supported by a grant of the Romanian National Authority for Scientific Research, CNCS-UEFISCDI, project number PN-II-ID-PCE-2011-3-0094, while for the third author, this work was possible with the financial support of the Sectoral Operational Programme for Human Resources Development 2007-2013, co-financed by the European Social Fund, under the project number POSDRU/107/1.5/S/76841 with the title Modern Doctoral Studies: Internationalization and Interdisciplinarity. (2) The authors are thankful to the reviewers for the careful reading of the paper and fruitful comments which improved the quality of the paper in a significant way.

Received: 10 December 2012 Accepted: 29 July 2013 Published: 14 August 2013

\section{References}

1. Perov, Al: On the Cauchy problem for a system of ordinary differential equations. Pviblizhen. Met. Reshen, Differ. Uravn. 2, 115-134 (1964)

2. Perov, Al, Kibenko, AV: On a certain general method for investigation of boundary value problems. Izv. Akad. Nauk SSSR, Ser. Mat. 30, 249-264 (1966) (in Russian)

3. Bucur, A, Guran, L, Petruşel, A: Fixed points for multivalued operators on a set endowed with vector-valued metrics and applications. Fixed Point Theory 10(1), 19-34 (2009)

4. Agarwal, RP: Contraction and approximate contraction with an application to multi-point boundary value problems. J. Comput. Appl. Math. 9, 315-325 (1983)

5. Filip, AD, Petruşel, A: Fixed point theorems on spaces endowed with vector-valued metrics. Fixed Point Theory Appl. 2010, Article ID 281381 (2009)

6. O'Regan, D, Shahzad, N, Agarwal, RP: Fixed Point Theory for Generalized Contractive Maps on Spaces with Vector-Valued Metrics. Fixed Point Theory and Applications, pp. 143-149. Nova Science Publishers, New York (2007)

7. Precup, R, Viorel, A: Existence results for systems of nonlinear evolution equations. Int. J. Pure Appl. Math. 47(2), 199-206 (2008)

8. Precup, R, Viorel, A: Existence results for systems of nonlinear evolution inclusions. Fixed Point Theory 11(2), 337-346 (2010)

9. Precup, $\mathrm{R}$ : The role of matrices that are convergent to zero in the study of semilinear operator systems. Math. Comput. Model. 49, 703-708 (2009)

10. Petruşel, A: Multivalued weakly Picard operators and applications. Sci. Math. Jpn. 59, 169-202 (2004)

11. Petre, IR, Petruşel, A: Krasnoselskii's theorem in generalized Banach spaces and applications. Electron. J. Qual. Theory Differ. Equ. 85, 1-20 (2012)

12. Rezapour, S, Amiri, P: Some fixed point results for multivalued operators in generalized metric spaces. Comput. Math. Appl. 61, 2661-2666 (2011)

13. Opoitsev, Vl: Heterogenic and combined-concave operators. Syber. Math. J. 16, 781-792 (1975) (in Russian) 
14. Opoitsev, VI: Dynamics of collective behavior. III. Heterogenic systems. Avtom. Telemeh. 36, 124-138 (1975) (in Russian)

15. Opoitsev, VI, Khurodze, TA: Nonlinear Operators in Spaces with a Cone, p. 271. Tbilis. Gos. Univ., Tbilisi (1984) (in Russian)

16. Guo, D, Lakshmikantham, V: Coupled fixed points of nonlinear operators with applications. Nonlinear Anal. 11, 623-632 (1987)

17. Gnana Bhaskar, T, Lakshmikantham, V: Fixed point theorems in partially ordered metric spaces and applications. Nonlinear Anal. 65, 1379-1393 (2006)

18. Lakshmikantham, V, Ćirić, L: Coupled fixed point theorems for nonlinear contractions in partially ordered metric spaces. Nonlinear Anal. 70, 4341-4349 (2009)

19. Guo, D, Cho, YJ, Zhu, J: Partial Ordering Methods in Nonlinear Problems. Nova Science Publishers, Hauppauge (2004)

20. Hong, S: Fixed points for mixed monotone multivalued operators in Banach spaces with applications. J. Math. Anal. Appl. 337, 333-342 (2008)

21. Rus, MD: The method of monotone iterations for mixed monotone operators. PhD thesis, Babeş-Bolyai University Cluj-Napoca (2010)

22. Berinde, $\mathrm{V}$ : Generalized coupled fixed point theorems for mixed monotone mappings in partially ordered metric spaces. Nonlinear Anal. 74, 7347-7355 (2011)

23. Luxemburg, WAJ, Zaanen, AC: Riesz Spaces I, vol. 1. North-Holland, Amsterdam (1971)

24. Luxemburg, WAJ, Zaanen, AC: Riesz Spaces II. North-Holland, Amsterdam (1983)

25. Zabrejko, PP: K-metric and K-normed linear spaces: survey. Collect. Math. 48(4-6), 825-859 (1997)

26. Huang, L-G, Zhang, X: Cone metric spaces and fixed point theorems of contractive mappings. J. Math. Anal. Appl. 332, 1468-1476 (2007)

27. Varga, RS: Matrix Iterative Analysis. Springer Series in Computational Mathematics, vol. 27. Springer, Berlin (2000)

28. Allaire, G, Kaber, SM: Numerical Linear Algebra. Springer, New York (2008)

29. Petruşel, A, Rus, IA: The theory of a metric fixed point theorem for multivalued operators. In: Lin, LJ, Petrusel, A, Xu, HK (eds.) Fixed Point Theory and Its Applications, pp. 167-176. Yokohama Publ., Yokohama (2010)

30. Urs, C: Coupled fixed point theorems and applications. Miskolc Math. Notes 14(1), 323-333 (2013)

31. Berinde, M, Berinde, V: On a general class of multi-valued weakly Picard mappings. J. Math. Anal. Appl. 326, 772-782 (2007)

32. Rus, IA: The theory of a metrical fixed point theorem: theoretical and applicative relevances. Fixed Point Theory 9(2), $541-559(2008)$

33. Rus, IA: Remarks on Ulam stability of the operatorial equations. Fixed Point Theory 10(2), 305-320 (2009)

34. Rus, IA, Petruşel, A, Sîntămărian, A: Data dependence of the fixed points set of some multivalued weakly Picard operators. Nonlinear Anal. 52, 1947-1959 (2003)

35. Bota, M, Petruşel, A: Ulam-Hyers stability for operatorial equations. An. Stiint. Univ. Al. I. Cuza lasi. Mat. (N.S.) 57, 65-74 (2011)

36. Petru, PT, Petruşel, A, Yao, JC: Ulam-Hyers stability for operatorial equations and inclusions via nonself operators. Taiwan. J. Math. 15(5), 2195-2212 (2011)

37. Petruşel, A, Rus, IA: Fixed point theorems in ordered L-spaces. Proc. Am. Math. Soc. 134(2), 411-418 (2005)

doi:10.1186/1687-1812-2013-218

Cite this article as: Petruşel et al.: Vector-valued metrics, fixed points and coupled fixed points for nonlinear operators. Fixed Point Theory and Applications 2013 2013:218

\section{Submit your manuscript to a SpringerOpen ${ }^{\ominus}$ journal and benefit from:}

- Convenient online submission

- Rigorous peer review

- Immediate publication on acceptance

- Open access: articles freely available online

- High visibility within the field

- Retaining the copyright to your article 